\title{
Monro-Kellie Hypothesis: Increase of Ventricular CSF Volume after Surgical Closure of a Spinal Dural Leak in Patients with Spontaneous Intracranial Hypotension
}

\author{
(D)T. Dobrocky, (D) M. Rebsamen, (D) C. Rummel, (D). Häni, (DP. Mordasini, (D)A. Raabe, (DC.T. Ulrich, \\ (D). Gralla, (D)E.I. Piechowiak, and (D). Beck
}

\begin{abstract}
BACKGROUND AND PURPOSE: CSF loss in spontaneous intracranial hypotension disrupts a well-regulated equilibrium. We aimed to evaluate the volume shift between intracranial compartments in patients with spontaneous intracranial hypotension before and after surgical closure of the underlying spinal dural breach.
\end{abstract}

MATERIALS AND METHODS: In total, 19 patients with spontaneous intracranial hypotension with a proved spinal CSF leak investigated at our institution between July 2014 and March 2017 (mean age, 41.8 years; 13 women) were included. Brain MR imaging-based volumetry at baseline and after surgery was performed with FreeSurfer. In addition, the spontaneous intracranial hypotension score, ranging from 0 to 9 , with 0 indicating very low and 9 very high probability of spinal CSF loss, was calculated.

RESULTS: Total mean ventricular CSF volume significantly increased from baseline (15.3 mL) to posttreatment MR imaging (18.0 mL), resulting in a mean absolute and relative difference, $+2.7 \mathrm{~mL}$ and $+18.8 \%(95 \% \mathrm{Cl},+1.2$ to $+3.9 \mathrm{~mL} ; P<.001)$. The change was apparent in the early follow-up (mean, 4 days). No significant change in mean total brain volume was observed (1136.9 versus $1133.1 \mathrm{~mL}, P=.58$ ). The mean spontaneous intracranial hypotension score decreased from $6.9 \pm 1.5$ at baseline to $2.9 \pm 1.5$ postoperatively.

CONCLUSIONS: Our study demonstrated a substantial increase in ventricular CSF volume in the early follow-up after surgical closure of the underlying spinal dural breach and may provide a causal link between spinal CSF loss and spontaneous intracranial hypotension. The concomitant decrease in the spontaneous intracranial hypotension score postoperatively implies the restoration of an equilibrium within the CSF compartment.

ABBREVIATIONS: CSFVF $=$ CSF venous fistula; $M D E F T=$ modified driven equilibrium Fourier transform; $\mathrm{SIH}=$ spontaneous intracranial hypotension

S pontaneous intracranial hypotension (SIH) is an increasingly recognized disorder classically presenting with disabling orthostatic headache, which manifests within minutes after assuming the upright position and subsides after lying down. ${ }^{1,2} \mathrm{SIH}$ is widely believed to be triggered by CSF leakage from the intrathecal into the epidural compartment, which is usually due to an osteogenic microspur (calcified disc protrusion or spondylophyte) penetrating the dura or a leaky spinal nerve root diverticulum. ${ }^{3,4}$ Alternatively, a

Received April 15, 2020; accepted after revision July 13

From the Department of Diagnostic and Interventional Neuroradiology (T.D., C.R., P.M., J.G., E.I.P.), Support Center for Advanced Neuroimaging (M.R., C.R.), and

Department of Neurosurgery (L.H., A.R., C.T.U., J.B.), Inselspital, Bern University Hospital, University of Bern, Bern, Switzerland; and Department of Neurosurgery (J.B.), Medical Center-University of Freiburg, Freiburg, Germany.

E.I. Piechowiak and J. Beck contributed equally to this work.

Please address correspondence to Tomas Dobrocky, MD, Institute of Diagnostic and Interventional Neuroradiology, Inselspital, Bern University Hospital, University of Bern, Freiburgstr 8, CH-3010, Switzerland; e-mail: tomas.dobrocky@insel.ch

- Indicates open access to non-subscribers at www.ajnr.org

http://dx.doi.org/10.3174/ajnr.A6782
CSF venous fistula (CSFVF) may be the underlying cause and has been reported in $23 \%$ of patients with SIH by Farb et al. ${ }^{5-7}$

Physiologically, CSF is sealed and circulates within the confines of the dura while a precise balance between production and resorption is maintained. When a dural breach or a CSFVF occurs, perturbation of the system ensues, resulting in a disturbance of the equilibrium. According to the Monro-Kellie hypothesis, the total volume within the confines of the skull is constant and is the sum of the volumes in 3 main compartments: blood, brain parenchyma, and CSF. ${ }^{8,9}$ Volume loss in one compartment is compensated by a reciprocal volume increase in the other compartments. In patients with SIH, the loss of CSF leads to a compensatory volume increase in the other compartments, which may be appreciated on brain imaging and includes meningeal enhancement, venous engorgement, and subdural hygroma. ${ }^{10,11}$ Although the sequelae of CSF loss in patients with SIH are widely recognized, volumetric analysis of the compartments has not yet been reported.

The goal of our study was to evaluate the volume of different intracranial compartments in SIH patients with a confirmed CSF 


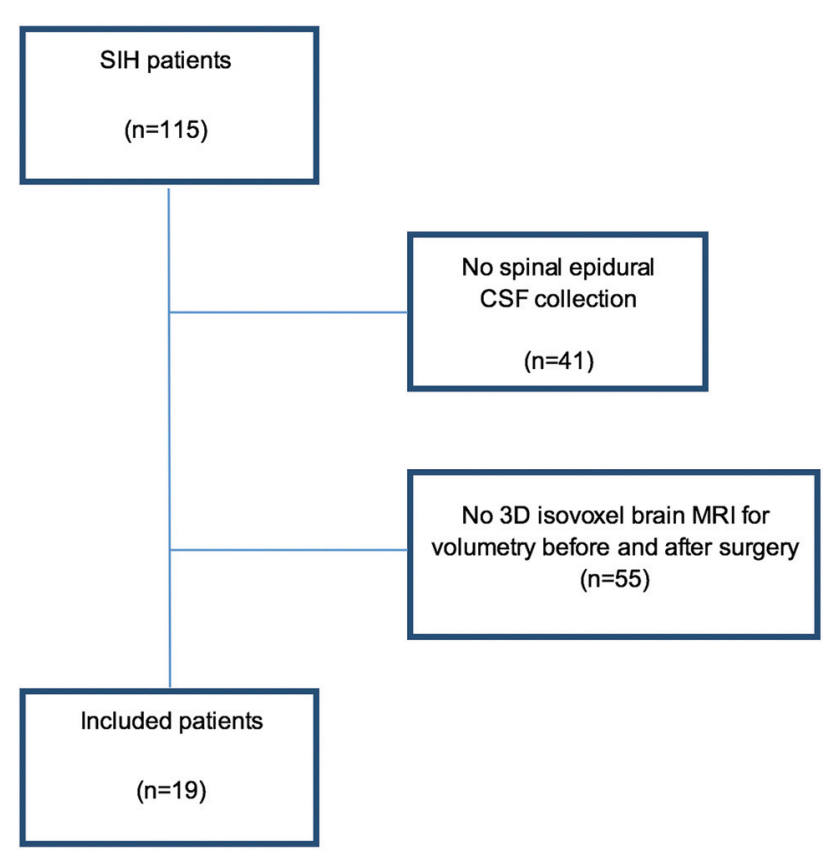

FIG 1. Flow chart of the included patients in our evaluation.

leak based on brain MR imaging before and after surgical closure of the leak.

\section{MATERIALS AND METHODS}

Institutional review board approval was obtained, and owing to the retrospective nature of the study, the need for informed consent was waived (Ethikkommission Bern). All consecutive patients with $\mathrm{SIH}$ diagnosed according to the International Classification of Headache Disorders, ${ }^{12}$ referred to our institution between July 2014 and March 2017, were screened. Subgroups of patients have previously been included in other studies, which have investigated different outcome measures including optic nerve sheath ultrasonography, surgical details of dural closure, CSF dynamics, spinal imaging, and brain MR imaging, but did not report on brain volumetry. ${ }^{11,13-16}$

Inclusion criteria were the following: 1) positive spinal imaging demonstrating an epidural CSF collection on MR imaging and postmyelography CT; 2) conventional dynamic myelography or dynamic CT myelography demonstrating the level of spinal CSF leakage; 3 ) surgical exploration and closure of the dural leak; 4) pretreatment brain MR imaging with isotropic, unenhanced T1-weighted sequences performed $<7$ days before surgery; 5) posttreatment brain MR imaging with isotropic, unenhanced T1-weighted sequences performed $<7$ days after surgery. Patients with post-lumbar puncture headache, poor-quality MR imaging, or absence of an isotropic T1weighted sequence were excluded (Fig 1, study flow chart).

The brain and spine imaging of all subjects was assessed by 1 board-certified neuroradiologist (T.D.) with 9 years of experience.

\section{Brain MR Imaging}

MR imaging before and after surgical closure of the dural defect was performed on a $1.5 \mathrm{~T}$ or $3 \mathrm{~T}$ scanner (Magnetom Avanto and Magnetom Verio; Siemens) with a standard circularly polarized 12-channel phased array head coil.
Routine MRI pulse sequences included precontrast transverse T1-weighted (TR/TE 600/14 ms) spin-echo (SE), transverse T2weighted (4100/100 ms) turbo SE images: slice thickness $5 \mathrm{~mm}$; field of view (FOV) $192 \times 220$, and a $294 \times 448$ matrix size, coronal FLAIR images (8500/89/2440 ms [TR/TE/TI]; slice thickness: 4 $\mathrm{mm}$; FOV $192 \times 220 \mathrm{~mm}$; acquisition time 1 minute 51 seconds; $358 \times 512$ matrix size). Postcontrast sagittal T1-weighted MPRAGE and coronal FLAIR fat-saturated images were acquired.

All patients received gadobutrol, $0.1 \mathrm{~mL} / \mathrm{kg}$ body weight (1.0 mol/L, Gadovist; Bayer Schering Pharma) with a flow rate of $5 \mathrm{~mL} / \mathrm{s}$, followed by $20 \mathrm{~mL}$ of sodium chloride with the same flow rate. All patients underwent cranial MR imaging for clinical reasons, and because it was not part of a dedicated study protocol, the acquired sequences were not identical.

Images acquired using an unenhanced T1-weighted 3D modified driven equilibrium Fourier transform (MDEFT) sequence $(\mathrm{TR} / \mathrm{TE}=7.92 / 2.48 \mathrm{~ms}$, section thickness $=1 \mathrm{~mm}$, number of averages $=1, \mathrm{FOV}=256 \times 256 \mathrm{~mm}$, FOV phase $=50 \%$, flip angle $=16^{\circ}$, acquisition time $=13$ minutes and 45 seconds, matrix size $=256 \times 256$ ) were used for volumetry.

\section{Brain SIH Score}

This 9-point scoring system helps to predict the likelihood of a CSF leak in patients with suspected SIH. ${ }^{11}$ The score is based on the 6 most relevant imaging findings: 3 major (2 points each), pachymeningeal enhancement, engorgement of the venous sinus, and effacement of the suprasellar cistern $(\leq 4.0 \mathrm{~mm})$; and 3 minor findings ( 1 point each), subdural fluid collection, effacement of the prepontine cistern $(\leq 5.0 \mathrm{~mm})$, and mamillopontine distance $(\leq 6.5 \mathrm{~mm})$. The $\mathrm{SIH}$ score was calculated before and after surgical closure of the dural defect. The total score was used to classify the patient's probability of having a spinal CSF leak: $\leq 2=$ low, $3-4=$ intermediate, and $\geq 5=$ high.

\section{Brain Volumetry}

Brain volumetry was performed in patients with an, unenhanced T1-weighted MDEFT sequence acquired before and after surgical closure of the spinal dural breach. The images were run through the recon-all pipeline of the freely available software package FreeSurfer (https://surfer.nmr.mgh.harvard.edu/; Version 6.0.0). Briefly, the main processing steps of the FreeSurfer pipeline comprise intensity normalization, affine registration to a template (Talairach), bias field correction, skull-stripping, and nonlinear alignment to the Montreal Neurological Institute 305 atlas followed by a segmentation of tissue classes and subcortical structures using intensity and neighbor constraints. Besides tesselating the cortical surface and estimating morphometric parameters like cortical thickness and surface area, ${ }^{17}$ FreeSurfer also segments substructures of the entire brain volume (ventricles, basal ganglia, mesiotemporal structures, brain stem). ${ }^{18,19}$ The following intracranial compartments were segmented and provided in milliliters: ventricular CSF, considering the volume of each ventricle separately (lateral ventricles, third and fourth ventricles); GM and WM; and brain stem. (Fig 2). The choroid plexus was segmented as a separate structure and was not included to the ventricular volume. Each individual case was loaded in freeview in FreeSurfer (https://andysbrainbook.readthedocs.io/ en/latest/FreeSurfer/FS_ShortCourse/FS_06_Freeview.html) 


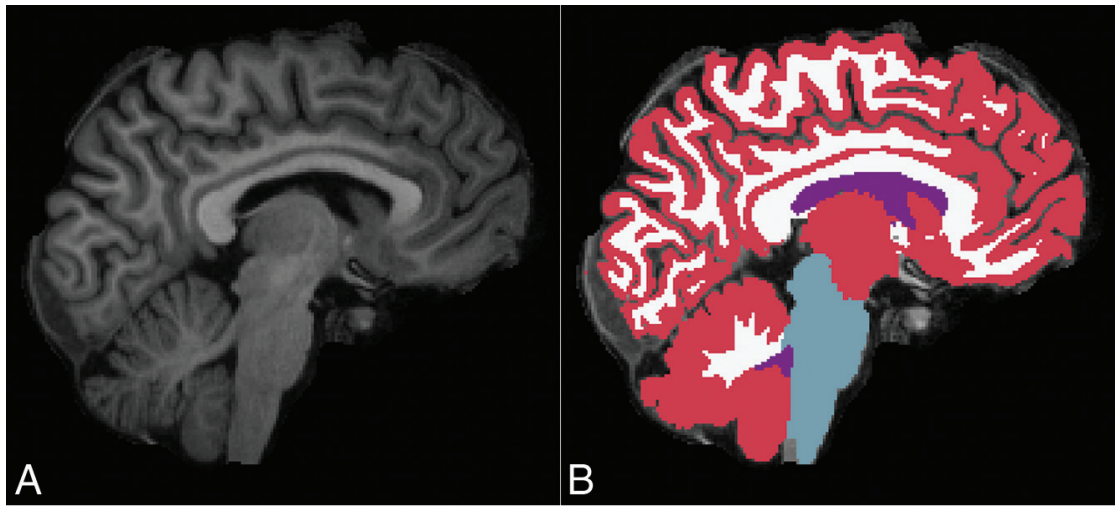

FIG 2. MDEFT sagittal image of a male patient after surgery $(A)$ with the corresponding FreeSurfer segmentation of gray matter (red), white matter (white), brain stem (light blue), and ventricular CSF (purple) (B).

variables. Differences between pretreatment and follow-up measurements were assessed with paired, 2-sided $t$ tests, with a significance threshold of $P<.05$. The relative change of volume was calculated as $100 \times$ (post-pre) $/$ pre $\%$. The differences between baseline and postsurgery volumetry were visualized with Tukey boxplots.

\section{RESULTS}

The final study population consisted of 19 patients (mean age, $41.8 \pm 12.9$ years; range, 25-70 years; 13 women, 6 men). The duration of clinical symptoms varied from a few days to several months. As shown on imaging and verified intraoperatively, the underlying

together with the corresponding segmentation for a manual review by M.R., experienced in brain volumetry, to ensure that ventricles were correctly identified and no outliers were erroneously included in the segmentation volume.

\section{Spine Imaging}

Our diagnostic technique has previously been described in detail. $^{15,20}$ Briefly, unenhanced and intrathecal gadoliniumenhanced spine MR imaging was performed first. The images were scrutinized for a spinal longitudinal extradural CSF collection or epidural contrast leakage indicative of a spinal CSF leak. Dynamic conventional myelography was then performed with the patient in the prone position when an osteogenic microspur was suspected or in a lateral decubitus position when a spinal nerve root diverticulum was the presumed source of leakage. The level at which the contrast agent exited the intrathecal compartment and started spilling into the epidural space was considered the level of the dural breach. Postmyelography CT was performed immediately thereafter to identify any underlying pathology, eg, a calcified microspur. None of our patients presented with a CSFVF.

\section{Surgical Closure of Dural Breach}

This technique has been previously described. ${ }^{3,21}$ In short, after interlaminar fenestration or hemilaminotomy, the ligamentum flavum was removed. In the case of a ventral dural leak. a dorsal durotomy and a spinal cord release maneuver were performed to gain access to the anterior dura. The ventral osseous microspur penetrating the dura was removed, the dura was sutured, and small intra- and epidural patches were placed for augmentation. If a tear was found in the nerve root sleeve, access to the diverticulum was gained via foraminotomy. The diverticulum was reduced and clipped or the dura was sutured before being wrapped with an external dura graft, such as DuraGen (Integra).

\section{Statistics}

The statistical analysis was performed using $\mathrm{R}$ with the stats package (Version 3.6.2; http://www.r-project.org/). Descriptive analysis was performed using frequencies and percentages for categoric variables and mean $( \pm \mathrm{SD})$ or median (interquartile range) for continuous pathology was a ventral microspur originating from an intervertebral disc or an endplate osteophyte in 14/19 cases (74\%) and a tear in the nerve root sleeve diverticulum in 5/19 cases (26\%). The median time (interquartile range) from baseline MR imaging to treatment and from treatment to follow-up MR imaging was $1[ \pm 1]$ day and $4[ \pm 2]$ days, respectively. The mean brain SIH score in our patients with a confirmed spinal CSF leak was $6.9 \pm 1.5$ preoperatively, and it decreased to $2.9 \pm 1.5$ after surgical closure of the dural breach (Fig 3). After surgery, 17 patients demonstrated clinical improvement, 1 patient remained unchanged, and 1 patient was lost to follow-up. The severity of pain was evaluated using the numeric rating scale ranging from 0 to 10 . The mean numeric rating scale decreased from $9.5 \pm 1.4$ before surgery to $2.5 \pm 2.3$ postinterventionally $(P<0.001)$.

The total mean ventricular CSF volume significantly increased from baseline $(15.3 \mathrm{~mL})$ to posttreatment MR imaging $(18.0 \mathrm{~mL})$, resulting in a mean absolute and relative difference of $+2.7 \mathrm{~mL}$ and $18.8 \%$ (95\% CI, +1.2 to $+3.9 \mathrm{~mL} ; P=.001)$ (Fig 4). A decrease in total ventricular CSF volume after the surgery was observed in 1 patient $(-0.5 \%)$, whereas the remaining 18 patients demonstrated volume increase between $5.9 \%$ and $65.4 \%$. The increase in ventricular CSF volume was statistically significant for all comp-artments: lateral ventricles $(+18.7 \%, P=.001)$, third ventricle $(+25.5 \%, P=$ $.001)$, and fourth ventricle $(+20.9 \%, P=.008)$ (Table and Fig 5). No significant change in mean total brain volume was observed (1136.9 versus $1133.1 \mathrm{~mL}$, mean absolute and relative difference, $-3.8 \mathrm{~mL}$ and $-0.3 \%$ [95\% CI, 0 to $-7.6 \mathrm{~mL}$ ] $P=.58$ ); either for GM (652.0 versus $644.8 \mathrm{~mL} ; P=.18)$ or $\mathrm{WM}$ (458.7 versus $462.4 \mathrm{~mL} ; P=.27)$.

\section{DISCUSSION}

Our data clearly demonstrate a substantial increase in ventricular CSF volume $(+18.8 \%, P=.001)$ after surgical closure of the underlying spinal dural breach and thus may provide a causal link between spinal CSF loss and SIH. While alterations in CSF volume are minuscule and may hardly be appreciated by $2 \mathrm{D}$ measurements, volumetric analysis reliably demonstrates the change. The increase in ventricular CSF volume may be demonstrated in the 


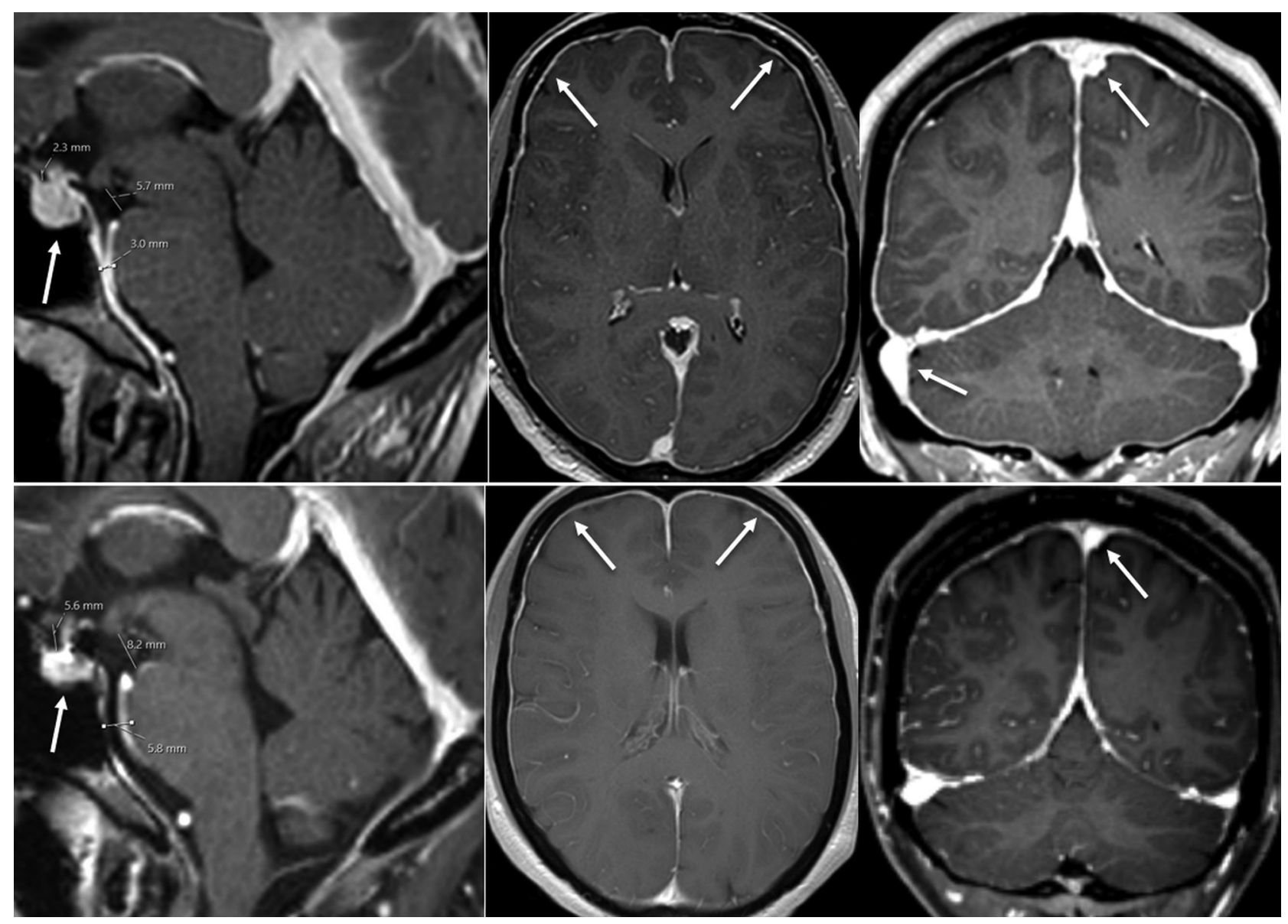

FIG 3. Female patient with a myleographically proved spinal CSF leak (not shown). Upper row, MR imaging performed before spinal surgery demonstrates typical findings of intracranial hypotension-SIH score $=8$ : pachymeningeal enhancement (2 points), engorgement of venous sinus (2 points), effacement of the suprasellar cistern ( $\leq 4.0 \mathrm{~mm}, 2$ points), no subdural fluid collection (0 points), effacement of the prepontine cistern ( $\leq 5.0 \mathrm{~mm}, 1$ point), and mamillopontine distance ( $\leq 6.5 \mathrm{~mm}, 1$ point). Lower row, MR imaging performed after surgery demonstrates almost complete resolution of all findings: SIH score 2, due to residual dural enhancement. Note also the decrease in pituitary size (arrow).

early postoperative stage (mean, 4 days) and is paralleled by a decrease in the SIH score, which implies the restoration of an equilibrium within the CSF compartment. CSF opening pressure, on the other hand, is an insufficient diagnostic criterion because most patients with a spinal CSF leak present a normal pressure. As reported by Kranz et al, ${ }^{22}$ only $34 \%$ of patients with confirmed $\mathrm{SIH}$ had an opening pressure of $<6 \mathrm{~cm} \mathrm{H}_{2} \mathrm{O}$.

Although volumetric analysis is time-demanding and usually not available in clinical routine, it may be a helpful tool in selected cases. For instance, in rebound intracranial hypertension, a phenomenon described in SIH patients after surgical closure of the leak, in whom the symptoms may resemble those of intracranial hypotension and make clinical discrimination challenging, however essential, because therapy is contrarious. In these cases, volumetric analysis may help to differentiate both and guide further treatment.

According to the Monro-Kellie doctrine, the sum of the volumes of brain parenchyma, CSF, blood, extracellular fluid, and meninges is constant within the rigid confines of the skull. ${ }^{23}$ Thus, CSF loss is compensated by a reciprocal increase of volume in the other compartments to maintain the equilibrium. However, each compartment may not deserve the equal weighting implied by this static concept. ${ }^{9}$
When CSF loss occurs, the CSF production rate is insufficient to maintain an equilibrium within the compartment. Although there is 1 report that speculates that increased CSF production in the early phase of SIH may occur, this mechanism may not be adequate. ${ }^{24}$ Second, the intracranial blood volume, which averages $\sim 100$ $130 \mathrm{~mL}$ ( $\sim 15 \%$ arterial, $\sim 40 \%$ venous, and $\sim 45 \%$ in the microcirculation), may increase. ${ }^{9}$ The venous structures usually become enlarged and more conspicuous on imaging, leading to sinus distension, pachymeningeal enhancement, or pituitary hyperemia. ${ }^{25,26}$ Third, extra-axial fluid collections to compensate for the volume loss may be observed. ${ }^{27}$

To depict the change in the blood volume and extraventricular CSF, the SIH score summarizing venous engorgement, dural enhancement, subdural collections, and effacement of the extraventricular CSF compartment (suprasellar, prepontine effacement; decrease in mamillopontine distance) was used in our study. The SIH score ranges from 0 to 9 , with 0 indicating very low and 9 indicating a very high probability of spinal CSF loss. We believe that applying the score more appropriate than comparing each imaging sign separately. Furthermore, only imaging signs with high interrater agreement are considered for its calculation, while other imaging signs with low interrater agreement 

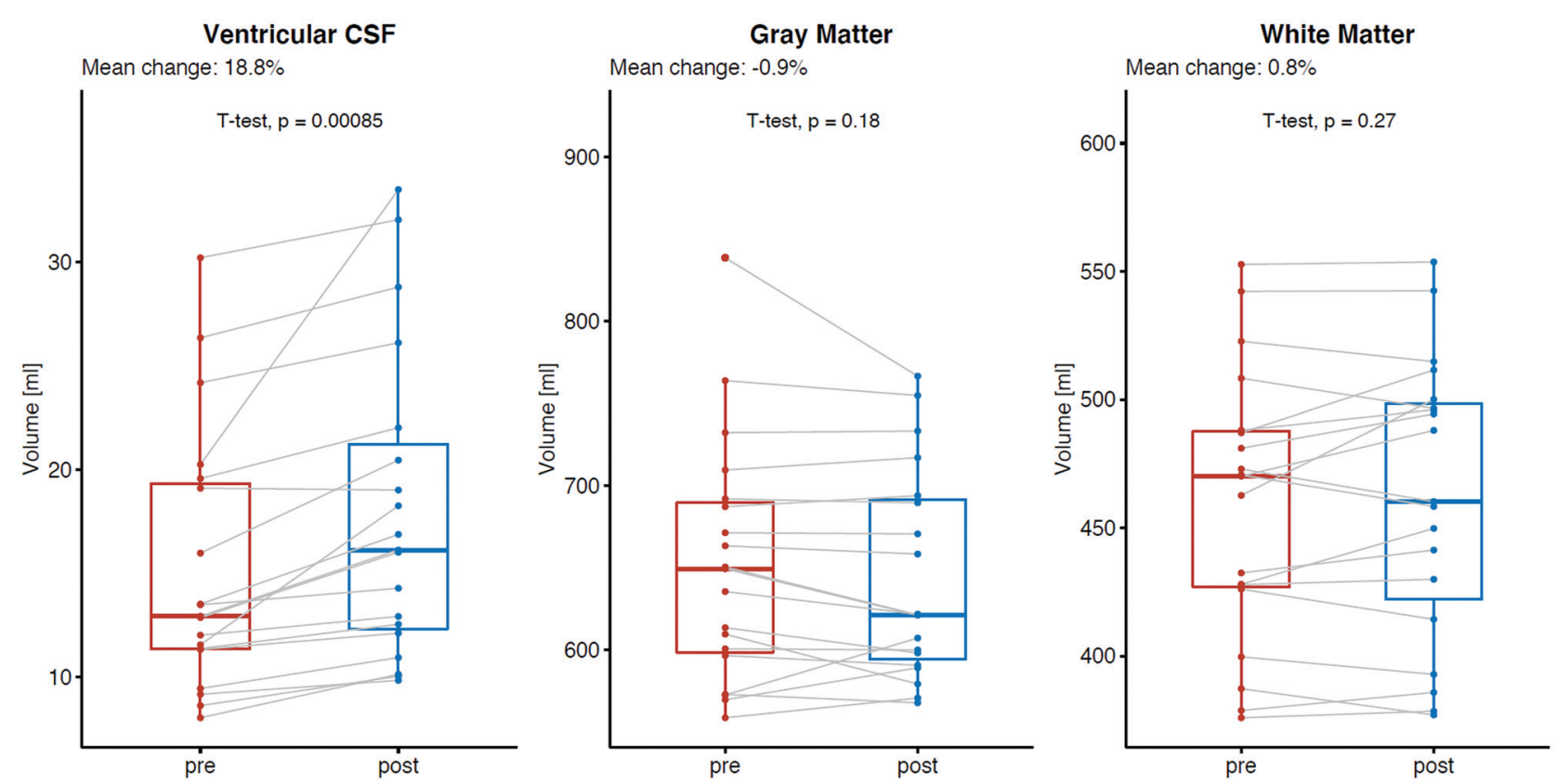

FIG 4. Mean absolute and relative change in volume between baseline and after surgical closure of the dural breach in patients with spontaneous intracranial hypotension: ventricular CSF (left, mean relative change, $+18.8 \%, P=.001$ ), total gray matter (middle, mean relative change, $-0.9 \%, P=.18$ ), and total white matter (right, mean relative change, $+0.8 \%, P=.27$ ).

Volumetry results for different intracranial compartments ${ }^{a}$

\begin{tabular}{lccccc}
\hline & $\begin{array}{c}\text { Before } \\
\text { Surgery }\end{array}$ & $\begin{array}{c}\text { After Surgical Closure of Spinal } \\
\text { Dural Tear }\end{array}$ & $\begin{array}{c}\text { Difference: Absolute } \\
\text { and Relative }\end{array}$ & $\begin{array}{c}P \\
\text { Value }\end{array}$ & $\begin{array}{c}\text { Measurement } \\
\text { Uncertainty }\end{array}$ \\
\hline SIH score & $6.9 \pm 2.2$ & $2.9 \pm 1.7$ & & $<.001$ & \\
Ventricular CSF $(\mathrm{mL})$ & $15.3 \pm 6.3$ & $18.0 \pm 7.4$ & $+2.7(+18.8 \%)$ & $<.001$ & 0.2 \\
Lateral ventricle $(\mathrm{mL})$ & $12.9 \pm 5.9$ & $15.2 \pm 6.9$ & $+2.3(+18.7 \%)$ & $<.001$ & 0.2 \\
Third ventricle $(\mathrm{mL})$ & $0.8 \pm 0.4$ & $1.0 \pm 0.3$ & $+0.2(+25.5 \%)$ & $<.001$ & 0.02 \\
Fourth ventricle $(\mathrm{mL})$ & $1.5 \pm 0.4$ & $1.8 \pm 0.4$ & $+0.3(+20.9 \%)$ & .008 & 0.05 \\
Total brain parenchyma $(\mathrm{mL})$ & $1136.9 \pm 116.6$ & $1133.1 \pm 111.0$ & $-3.8(-0.3 \%)$ & .58 & 7.6 \\
Gray matter $(\mathrm{mL})$ & $652.0 \pm 73.7$ & $644.8 \pm 64.3$ & $-7.2(-0.9 \%)$ & .18 & 7.3 \\
White matter $(\mathrm{mL})$ & $458.7 \pm 53.0$ & $462.4 \pm 54.9$ & $+3.7(+0.8 \%)$ & .27 & 10.8 \\
Brain stem & $22.9 \pm 3.6$ & $22.7 \pm 3.5$ & $-0.2(-0.9 \%)$ & .34 & 0.2 \\
\hline
\end{tabular}

${ }^{a}$ Measurements show the mean volume in milliliters; the only exception is the SIH score in the first line.

proposed in the literature are not included. ${ }^{11}$ The mean SIH score was $6.9 \pm 1.5$ at baseline and decreased to $2.9 \pm 1.5$ after surgical closure. This outcome translates into less conspicuous venous structures and meningeal enhancement and normalization of the extraventricular CSF compartment postoperatively.

Minor variations of ventricular volume may reflect variations in hydration status. As reported by Dickson et al, ${ }^{28}$ in a single normally hydrated subject, the mean ventricular volume measured during 4 days showed a variation of $1.63 \%$. Furthermore, in repeated volumetric analysis, an error inherent to the technique itself should be considered. To estimate this error, we refer to Rummel et al, ${ }^{29}$ who have performed repeat MRIs in healthy subjects within $<2$ years (31 subjects with a total of brain 87 MRIs) to derive the measurement uncertainty and have reported volume uncertainties of $0.2 \mathrm{~mL}$ for the ventricular CSF.

However, the change in intracranial CSF volume presented in our study population clearly outweighs the level of error that could be expected. The ventricular CSF volume after surgery is in line with values reported in healthy individuals. ${ }^{30}$
Our study did not demonstrate any significant change in the total volume of brain parenchyma after surgical closure of a dural breach. Brain tissue volume is generally considered invariable, and short-term changes are not expected.

Similar results for spinal CSF were reported in a thresholdbased spine MR volumetry study in patients with SIH. Chen at $\mathrm{al}^{31}$ demonstrated a significant increase in intraspinal CSF between baseline and recovery $(72.31$ versus $93 \mathrm{~mL}, P<.001$ ). The authors concluded that an increase in intraspinal CSF volume was related to disease recovery.

Limitations of the present study include the low number of patients with SIH with an available MDEFT sequence appropriate for volumetry. Second, only patients with a dural breach were included, not considering those with other etiologies like CSFVF. Third, extraventricular CSF and the intracranial blood volume compartments were not included in our volumetric analysis because they are not provided in FreeSurfer. In the authors' experience, other methods like the FMRIB Automated Segmentation Tool (http://fsl.fmrib.ox.ac.uk/fsl/fslwiki/fast), 

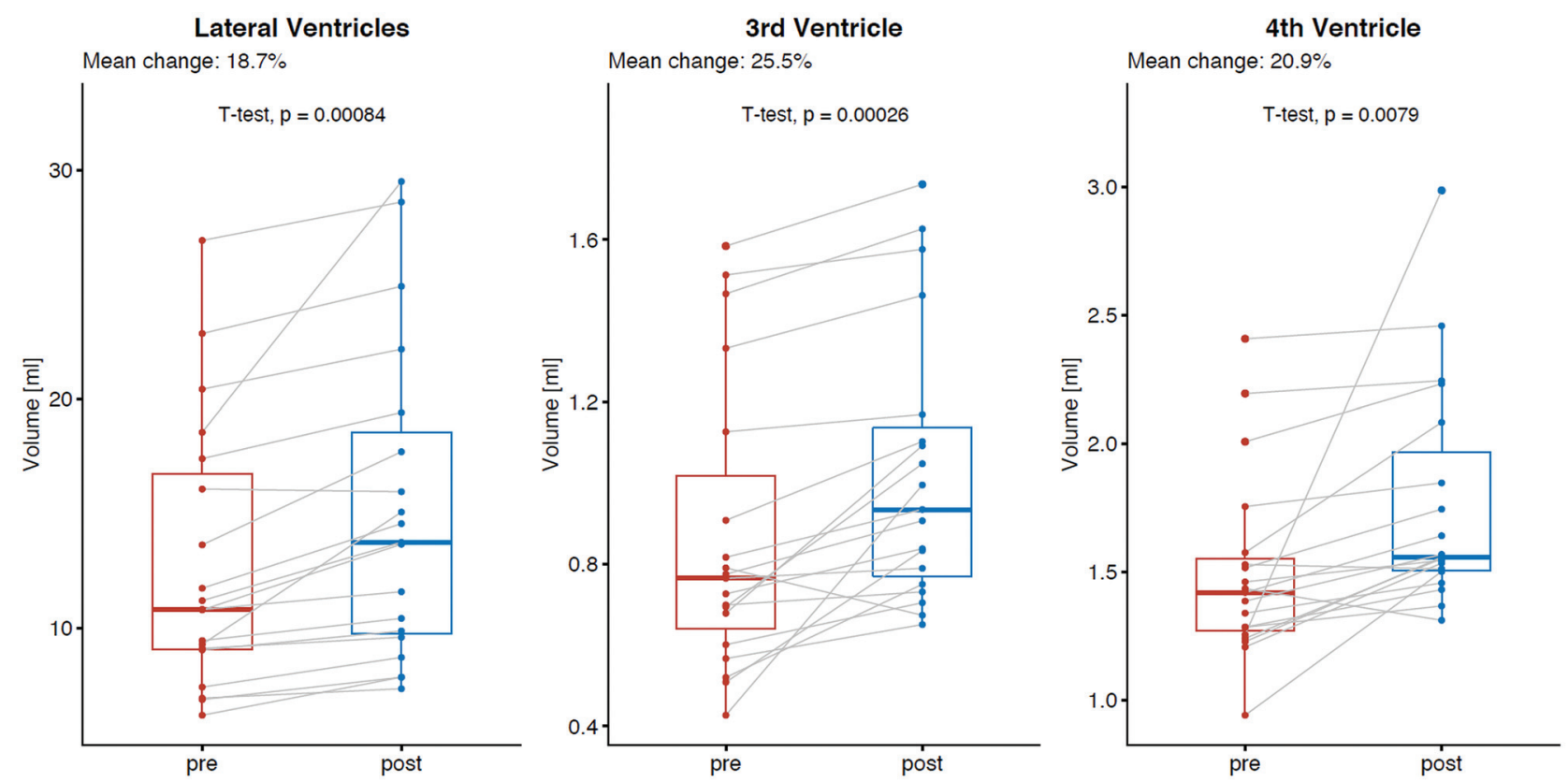

FIG 5. Mean absolute and relative changes in ventricular CSF volume between baseline and after surgical closure of the dural breach in patients with spontaneous intracranial hypotension for each ventricle separately: lateral ventricles (left, mean relative change, $+18.7 \%, P=.001$ ), third ventricle (mean relative change, $+25.5 \%, P=.001$ ), and fourth ventricle (mean relative change, $+20.9 \%, P=.008$ ).

which includes extraventricular CSF, are not reliable due to erroneous outer delineations of the subarachnoid space and variations in skull-stripping. ${ }^{32}$

On the other hand, we provide results obtained in a very well-defined cohort of SIH patients SIH with myleographicallyproved spinal CSF leak. In addition, the spinal dural breach was verified intraoperatively before being sealed with a suture and an additional patch.

In summary, the continuing research on SIH has increased our understanding of the underlying causes. Our results are in line with the proposed mechanism of CSF depletion leading to compensatory processes. Finally, an increase in total ventricular CSF volume after surgical closure of the spinal breach indicates a restoration of an equilibrium within the CSF compartment that has been perturbed.

\section{CONCLUSIONS}

A substantial increase in ventricular CSF volume after surgical closure of the underlying dural breach in patients with SIH may be observed in the early postoperative stage. It may be a valuable indicator of recovery, providing a causal link between the spinal CSF loss and SIH. The concomitant decrease in the SIH score postoperatively implies the restoration of an equilibrium within the CSF compartment and is in line with the Monro-Kellie hypothesis.

Disclosures: Michael Rebsamen—RELATED: Grant. Swiss National Science Foundation, Comments: This work was supported by the Swiss National Science Foundation under grant No.180365.* Jan Gralla—UNRELATED: Consultancy: Global Principal Investigator Swift Direct, Comments: stroke study funded by Medtronic*; Grants/ Grants Pending: Swiss National Science Foundation, Comments: stroke MRI study.* *Money paid to the institution.

\section{REFERENCES}

1. Schievink WI. Spontaneous spinal cerebrospinal fluid and ongoing investigations in this area. JAMA 2006;295:2286-96 CrossRef Medline
2. Kranz PG, Gray L, Amrhein TJ. Spontaneous intracranial hypotension: 10 myths and misperceptions. Headache 2018;58:948-59 CrossRef Medline

3. Beck J, Ulrich CT, Fung C, et al. Diskogenic microspurs as a major cause of intractable spontaneous intracranial hypotension. Neurology 2016;87:1220-26 CrossRef Medline

4. Kranz PG, Stinnett SS, Huang KT, et al. Spinal meningeal diverticula in spontaneous intracranial hypotension: analysis of prevalence and myelographic appearance. AJNR Am J Neuroradiol 2013;34:1284-89 CrossRef Medline

5. Kranz PG, Amrhein TJ, Gray L. CSF venous fistulas in spontaneous intracranial hypotension: Imaging characteristics on dynamic and CT myelography. AJR Am J Roentgenol 2017;209:1360-66 CrossRef Medline

6. Kumar N, Diehn FE, Carr CM, et al. Spinal CSF venous fistula: a treatable etiology for CSF leaks in craniospinal hypovolemia. Neurology 2016;86:2310-12 CrossRef Medline

7. Farb RI, Nicholson PJ, Peng PW, et al. Spontaneous intracranial hypotension: a systematic imaging approach for CSF leak localization and management based on MRI and digital subtraction myelography. AJNR Am J Neuroradiol 2019;40:745-53 CrossRef Medline

8. Harvey C. The third circulation in studies in intracranial physiology and surgery. In: The Third Circulation in Studies in Intracranial Physiology and Surgery. Oxford University Press; 1926

9. Wilson MH. Monro-Kellie 2.0: the dynamic vascular and venous pathophysiological components of intracranial pressure. $J$ Cereb Blood Flow Metab 2016;36:1338-50 CrossRef Medline

10. Kranz PG, Tanpitukpongse TP, Choudhury KR, et al. Imaging signs in spontaneous intracranial hypotension: prevalence and relationship to CSF pressure. AJNR Am J Neuroradiol 2016;37:1374-78 CrossRef Medline

11. Dobrocky T, Grunder L, Breiding PS, et al. Assessing spinal cerebrospinal fluid leaks in spontaneous intracranial hypotension with a scoring system based on brain magnetic resonance imaging findings. JAMA Neurol 2019;76:580 CrossRef Medline

12. Headache Classification Committee of the International Headache Society (IHS): the International Classification of Headache Disorders, 3rd edition. Cephalalgia 2018; 38:1-211 CrossRef Medline 
13. Fichtner J, Ulrich CT, Fung C, et al. Sonography of the optic nerve sheath diameter before and after microsurgical closure of a dural CSF fistula in patients with spontaneous intracranial hypotension: a consecutive cohort study. Cephalalgia 2019;39:306-15 CrossRef Medline

14. Fichtner J, Ulrich CT, Fung C, et al. Management of spontaneous intracranial hypotension: transorbital ultrasound as discriminator. $J$ Neurol Neurosurg Psychiatry 2016;87:650-55 CrossRef Medline

15. Dobrocky T, Mosimann PJ, Zibold F, et al. Cryptogenic cerebrospinal fluid leaks in spontaneous intracranial hypotension: role of dynamic CT myelography. Radiology 2018;289:766-72 CrossRef Medline

16. Beck J, Fung C, Ulrich CT, et al. Cerebrospinal fluid outflow resistance as a diagnostic marker of spontaneous cerebrospinal fluid leakage. J Neurosurg Spine 2017;27:227-34 CrossRef Medline

17. Fischl B, Dale AM. Measuring the thickness of the human cerebral cortex from magnetic resonance images. Proc Natl Acad Sci U S A 2000;97:11050-55 CrossRef Medline

18. Fischl B, Salat DH, Busa E, et al. Whole brain segmentation: automated labeling of neuroanatomical structures in the human brain. Neuron 2002;33:341-55 CrossRef Medline

19. Fischl B, Salat DH, van der Kouwe AJ, et al. Sequence-independent segmentation of magnetic resonance images. Neuroimage 2004;23 (Suppl 1):S69-84 CrossRef Medline

20. Kranz PG, Luetmer PH, Diehn FE, et al. Myelographic techniques for the detection of spinal CSF leaks in spontaneous intracranial hypotension. AJR Am J Roentgenol 2016;206:8-19 CrossRef Medline

21. Beck J, Raabe A, Schievink WI, et al. Posterior approach and spinal cord release for $360^{\circ}$ repair of dural defects in spontaneous intracranial hypotension. Neurosurgery 2019;84:E345-51 CrossRef Medline
22. Kranz PG, Tanpitukpongse TP, Choudhury KR, et al. How common is normal cerebrospinal fluid pressure in spontaneous intracranial hypotension? Cephalalgia 2016;36:1209-17 CrossRef Medline

23. Monro A. Observations on Structure and Functions of the Nervous System. Creech and Johnson; 1783

24. Häni L, Fung C, Jesse CM, et al. Insights into the natural history of spontaneous intracranial hypotension from infusion testing. Neurology 2020;95:e247-55 CrossRef Medline

25. Fishman RA, Dillon WP. Dural enhancement and cerebral displacement secondary to intracranial hypotension. Neurology 1993;43:60911 CrossRef Medline

26. Savoiardo M, Armenise S, Spagnolo P, et al. Dural sinus thrombosis in spontaneous intracranial hypotension: hypotheses on possible mechanisms. J Neurol 2006;253:1197-202 CrossRef Medline

27. Beck J, Gralla J, Fung C, et al. Spinal cerebrospinal fluid leak as the cause of chronic subdural hematomas in nongeriatric patients. $J$ Neurosurg 2014;121:1380-87 CrossRef Medline

28. Dickson JM, Weavers HM, Mitchell N, et al. The effects of dehydration on brain volume: preliminary results. Int J Sports Med 2005;26:481-85 CrossRef Medline

29. Rummel C, Aschwanden F, McKinley R, et al. A fully automated pipeline for normative atrophy in patients with neurodegenerative disease. Front Neurol 2017;8:727 CrossRef Medline

30. Blatter DD, Bigler ED, Gale SD, et al. Quantitative volumetric analysis of brain MR: normative database spanning $\mathbf{5}$ decades of life AJNR Am J Neuroradiol 1995;16:241-51 Medline

31. Chen HC, Chen PL, Tsai YH, et al. Quantitative measurement of CSF in patients with spontaneous intracranial hypotension. AJNR Am J Neuroradiol 2017;38:1061-67 CrossRef Medline

32. Patenaude B, Smith SM, Kennedy DN, et al. A Bayesian model of shape and appearance for subcortical brain segmentation. Neuroimage 2011;56:907-22 CrossRef Medline 